\title{
LA ADAPTACIÓN CINEMATOGRÁFICA A LA LUZ DE ALGUNAS APORTACIONES TEÓRICAS RECIENTES*
}

\author{
José Antonio PÉREZ BOWIE \\ Universidad de Salamanca
}

\section{PRELIMINAR}

El ámbito que abarcan las relaciones entre cine y literatura es tan amplio como heterogéneo ya que no se limita a los problemas derivados de la adaptación fílmica de textos literarios, sino que se extiende a otras muchas parcelas, tales como el estudio de las relaciones entre un determinado escritor y el medio cinematográfico, los estudios de carácter histórico

* Este trabajo se inscribe en el marco del Proyecto PB98-0267 financiado por la Dirección General de Investigación del Ministerio de Educación y Cultura. Una versión más ampliada de él puede encontrarse en «La teoría sobre la adaptación cinematográfica de textos literarios. Estado de la cuestión», estudio introductorio a J.A. Pérez Bowie (ed.), La adaptación cinematográfica de textos literarios. Teoría y práctica, Salamanca: Plaza Universitaria Ediciones, 2003. 
sobre la adaptación, los de las relaciones generales entre literatura y cine, los manuales de guión que abarcan igualmente aspectos vinculados a la adaptación o los estudios de tipo metateórico (Cattrysse, 1992: 2). En definitiva, las relaciones entre ambos medios abarcarían, por una parte, las influencias de la literatura sobre el cine, la del cine sobre la literatura y la existencia de los numerosos fenómenos de intertextualidad entre ambos, como los que se producen en aquellas obras que elaboran un lenguaje mixto o una especie de fusión del lenguaje literario y el cinematográfico o en aquella otras de difícil ubicación genérica como novelas-filme, cinedramas, poemas cinematográficos, etc. El objetivo de estas páginas va a ser, no obstante, el de revisar algunas de las aproximaciones recientes al fenómeno de la adaptación a la pantalla de textos literarios y calibrar los avances que han supuesto tanto en lo referente a precisión teórica como a la aportación de un instrumental metodológico de considerable eficacia.

Hay que comenzar señalando cómo la propia etiqueta de «adaptación», mantenida por pura inercia, es cuestionada por muchos de los estudiosos del fenómeno, por la inoperancia de la misma para designar la heterogénea variedad de productos que suelen agruparse bajo ella. Existen, así, intentos de distinguir entre los diversos grados de fidelidad que el filme guarda con relación al texto-fuente, que se traducen en tipologías diversas que vienen a ser variantes más o menos matizadas de la tríada ilustración/ recreación/ creación, términos que han sido objeto de rectificaciones por parte de quienes han intentado redefinirlos a partir de nuevos criterios clasificatorios. El intento de acuñar una terminología más satisfactoria que sirva para dar cuenta de la variedad de facetas que presenta el fenómeno — traducción, traslación, transposición, etc.viene a ser un síntoma de la complejidad del mismo y de la dificultad de atraparlo mediante esquemas reductores. Las opciones más recientes se inclinan por rechazar las tipologías cuyas premisas están excesivamente vinculadas a criterios contenidistas y sostienen que el problema de la adaptación ha de ser abordado desde niveles de mayor complejidad, atendiendo primordialmente a las diferencias de lenguaje. Se defiende, así, la etiqueta de recreación, por admitir que en la transformación fílmica de un texto literario precedente no cabe hablar de la superioridad de éste con relación al producto resultante sino de una igualdad entre lenguajes diversos, en tanto que el paso de una estructura significante a otra implica también que se modifique la estructura de la significación; aparte de que, asimismo, varía la situación comunicativa entre los usuarios de 
ambos mensajes y su forma de consumo y de que el proceso transposicional se orienta más al sistema de llegada que al de partida (Fernández, 2002: 13-14).

A la complejidad derivada de la amplitud de fenómenos englobables bajo la etiqueta de «adaptación» habría que sumar las dificultades que entraña el proceso adaptador entre las que se encuentran las inherentes a la diversidad de los lenguajes utilizados por el texto de partida y por el texto final, las imputables a la defectuosa comprensión, análisis o lectura de aquél, las atribuibles a las limitaciones creativas y expresivas del adaptador o a otros co-creadores del producto final, sin olvidar las que impone el hecho de ser el cine, además de un arte, una industria sometida a un conjunto de reglas, convenciones y determinaciones económicas.

\section{ALGUNOS ANTECEDENTES}

Los nuevos enfoques metodológicos del fenómeno de la adaptación tienen en común el reconocimiento de la independencia entre el producto resultante y el texto de partida y, por consiguiente, la inoperancia de juzgar este último a partir de criterios que valoran la fidelidad con relación a aquél. Ya los formalistas rusos, los primeros en abordar de manera rigurosa la relaciones entre cine y literatura, introdujeron varios conceptos operativos comunes al análisis de ambos medios artísticos (forma, función, organización narrativa) e insistieron en la necesidad de distinguir entre dos lenguajes perfectamente diferenciados. Así, Eikhenbaum, en 1926, al referirse a la necesidad que el cine tiene de argumentos procedentes de la literatura, afirmaba que, pese a ello «de ningún modo se trata de someter el cine a la literatura», ya que en aquél, «incluso cuando la trama es adaptada, el argumento se organiza de manera original, en la medida en que los medios, los elementos mismos del discurso cinematográfico, son originales» (Eikhenbaum, 1998: 199-200).

Pero, hasta tiempos muy recientes, la perspectiva de quienes se enfrentan al fenómeno de la adaptación, ha sido la de defender la supremacía del texto literario: así André Bazin (1990: 116), Alain García (1990: 203), o George Bluestone; este último, a pesar de sostener la autonomía del filme sobre la novela, no conseguía prescindir del todo de las aserciones pres- 
criptivas respecto de la fidelidad al texto de partida (Bluestone, 1971: 6264 y 89-90) ${ }^{1}$. Pío Baldelli, en un ya clásico trabajo, tampoco perdía de vista la dependencia del filme adaptado con el texto original al establecer las posibles tipologías y distinguía tres categorías negativas (la adaptación con fines comerciales, la subordinación fiel al texto literario y el filme que rellena las indeterminaciones de aquél), para valorar positivamente una cuarta: aquella en que el texto literario sirve de partida para una creación original (Baldelli, 1966: 51).

Clasificaciones similares las encontramos en Geoffrey Wagner, quien distingue entre transposición (adaptación fiel), comentario (introducción de variantes) y analogía (máximo desvío derivado de la intención de hacer una obra artística diferente) (Wagner, 1975: 219-231); o Dudley Andrew, quien establece una tipología de la adaptación basada, igualmente, en tres grados: fuente reconocible, a pesar de las transformaciones a que ha sido sometida (préstamo), reflexión creativa sobre el texto literario, que puede llegar a ser un diálogo con aquél (intersección) y fidelidad al esquema narrativo del texto de partida, aunque se establezcan cambios en el tono, el ritmo, la instancia narradora, etc (fidelidad de transformación) (Andrew, 1984: 96-106) ${ }^{2}$. Este último introduce respecto de los anteriores la necesidad de diferenciar, a la hora de enfrentarse a un filme adaptado, entre el estrato discursivo y el estrato narrativo del texto fuente, afirmando que los filmes han de ser considerados en sí mismos como actos de discurso.

Las aproximaciones que desde la perspectiva de la semiótica se harán a partir de los años ochenta vienen ya, mayoritariamente, a centrar su atención en los aspectos discursivos del filme. Gianfranco Bettetini, por ejem-

1 Alain García, por ejemplo, quien distingue entre tres tipos posibles de adaptación, adaptación fiel, adaptación libre y transposición, viene a considerar, en definitiva, la fidelidad total a la letra y al espíritu de la obra adaptada como un valor positivo; así al referirse al tercer tipo de su clasificación comenta que en él, al conservarse el fondo de la novela y tratar de encontrar a la vez las equivalencias de su forma, ni la literatura ni el cine resultan traicionados.

2 Un resumen muy esclarecedor de los planteamientos citados puede encontrarse en Fernández (2002: 16-21), trabajo al que habrá que referirse más adelante por constituir una de las aportaciones teóricas más valiosas que desde el ámbito español se han hecho a la cuestión que nos ocupa. Una antología de los textos más significativos de algunos de estos teóricos se puede encontrar en el libro de Timothy Corrigan (1998), donde, además, el autor traza una panorámica de los distintos enfoques teóricos desde los que se han abordado las relaciones entre la literatura y el cine a lo largo del siglo XX. 
plo, es uno de los primeros en considerar la dimensión extratextual a la hora de enfrentarse a las prácticas adaptativas, reconociendo que el problema de la adaptación cinematográfica de una obra literaria no cabe ser abordado en el marco exclusivo de la translación de su universo semántico de una lengua natural a otra o de un sistema semiótico a otro sino que hay que llevar la atención al componente pragmático, puesto que todo texto es la manifestación de una estrategia comunicativa y su «traducción» exige la restauración de las instancias que participan en la enunciación (Bettetini, 1986: 93). Su clasificación del fenómeno ofrece, por lo demás, aportaciones novedosas al distinguir entre adaptaciones que son traducción fiel y respetuosa con la narración propuesta por el texto de partida, aquellas otras más atentas a la transposición de la «atmósfera ambiental» del texto-fuente, las que hacen prevalecer los valores ideológicos sostenidos en aquél, las que establece una confrontación con ese texto-fuente basada en el género en que se quiera adscribir la adaptación, con lo que se privilegian los elementos audiovisuales sobre los literarios, $\mathrm{y}$, por último, aquellas adaptaciones en que la matriz literaria es sólo un pretexto (generalmente narrativo) que después se desordena y reelabora en un universo de escritura casi siempre completamente autónomo respecto del original (Bettetini, 1986: 98-100) ${ }^{3}$.

${ }^{3}$ La mayor parte de los estudios sobre la adaptación siguen, no obstante, circunscritos a una perspectiva intertextual, seguidores atentos de la metodología instaurada por los análisis narratológicos pero sin desarrollar la dimensión pragmática contemplada por los mismos. Su supeditación a enfoques exclusivamente sincrónicos, que, sin duda, proporcionan una precisión terminológica y un instrumental muy rentables a la hora de explicar el proceso de transformación de la narración literaria en la cinematográfica. Ello determina que el objetivo de tales trabajos se limite al establecimiento y la sistematización de unos principios a partir de los cuales construir una metodología que permita el análisis de las relaciones entre el texto adaptado y el texto final. Se trata, por ello, de «recetarios» que renuncian a abordar el fenómeno desde una panorámica generalizadora para centrarse en los aspectos exclusivamente intratextuales a través de un desmenuzamiento riguroso de la morfología.

Una buena muestra de esta metodología es la monografía sobre el relato cinematográfico de André Gaudreault y François Jost (Gaudreault-Jost, 1995) bastante divulgada en su edición española; junto a ella se pueden mencionar las de Francis Vanoye (1995), Stuart Y. McDougal (1985) o la elaborada conjuntamente por los italianos Francesco Casetti y Federico di Chio (1994). Los presupuestos narratológicos han sido desarrollados y actualizados por los llamados investigadores neoformalistas como David Bordwell y Kristin Thompson que estudian el lenguaje fílmico en su condición de sistema de comunicación artística a la vez que analizan su funcionamiento en relación con la percepción del público, de los sistemas de convenciones que operan sobre él, y consideran la necesidad de ampliar su atención a las fuentes no fílmicas (Bordwell, 1996 y Bordwell-Thompson, 


\section{LA SUPERACIÓN DEL MARCO INTERTEXTUAL. APORTACIONES MÁS RELEVANTES}

Esta opción de abordar el problema de la adaptación desde una perspectiva pragmática superadora del estrecho marco de las relaciones intertextuales es la que ha proporcionado mayor rendimiento teórico a las aproximaciones más recientes. La atención al fenómeno de la adaptación, centrada casi exclusivamente en el nivel de los enunciados respectivos, ha ido desplazándose, propiciada por el cambio de paradigma experimentado en la teoría lingüística y literaria a partir de los años sesenta, hacia el nivel de la enunciación, abriendo interrogantes sobre las instancias que participaban en la misma y sobre los condicionamientos ejercidos por el contexto en que tenía lugar. En tal sentido, puede afirmarse que las reflexiones en torno al hecho de la adaptación han estado determinadas por el desarrollo de la teoría literaria y los diversos planteamientos de ésta — semiótica, pragmática, estética de la recepción, teoría de los polisistemas - han sido aplicados a la explicación de aquélla, con el resultado de un cada vez más notable aumento de la precisión de los análisis y de la matización de los fenómenos abordados.

Entre las aportaciones superadoras del marco exclusivamente intertextual, hay que referirse, en primer lugar, a la propuesta de Toury, quien aborda el estudio de la adaptación fílmica como un proceso de traducción. Parte para ello de la constatación de que ambas tienen como punto de partida un texto y producen textos y de que ambas representan a la vez un proceso de transformación y de transposición de textos, en cuanto que existe una serie de elementos invariantes que son transpuestos del texto 1 al texto 2 . Toury no postula como condición necesaria la existencia de una relación particular entre los sistemas semióticos subyacentes en cada texto (los procesos de transferencia textual son, así, irreversibles por lo que desde un texto 1 es posible llegar a diferentes textos 2 que se relacionen de diferente manera con aquél; y viceversa, es posible reconstruir diversos textos 1 hipotéti-

1995). Junto a los citados habría que aludir a otros trabajos elaborados ya desde una perspectiva totalmente empírica, dado que su finalidad es la de servir como manuales de adaptación proporcionando las pautas para la tarea práctica de convertir el texto literario en un filme, por lo carecen de toda pretensión teórica; un buen ejemplo lo constituiría el libro de Linda Segers (1993). 
cos a partir de un solo texto 2; los dos procedimientos instalan un contexto comunicativo análogo sobre varios puntos básicos, entre ellos las mismas instancias comunicativas (Toury, 1980: 19-24).

Otra de las aportaciones teóricas recientes en torno al fenómeno de la adaptación, destacable por su rigor y rentabilidad, es la de Patryck Cattrysse quien aborda la cuestión desde de teoría de los polisistemas formulada respecto de la literatura por Itamar Even Zohar. Cattrysse se apoya en la distinción que éste hace, a la hora de describir un sistema complejo como es la literatura, entre funcionamiento autónomo (la literatura en un sistema autoregulador, posee sus propios mecanismos normativos para organizar la conservación y la evolución de las prácticas literarias) y heterónomo (pero ese sistema no funciona en el vacío: las prácticas literarias están a la vez determinadas por factores externos). Por ello, el sistema literario no puede ser concebido aisladamente de los sistemas (artísticos y no artísticos, socio-culturales, políticos, etc.) de su entorno (Cattrysse, 1992: 32-33).

A partir de ahí establece que un estudio de la adaptación fílmica en términos de normas y de sistemas debe abordarla desde dos lados: por una parte, ha de plantear las cuestiones que conciernen a la adaptación en su contexto de llegada y, por otro, he de examinar cuáles son los mecanismos sistemáticos que han determinado el proceso transformacional de la adaptación. En otras palabras, se estudiará la adaptación como texto terminado o como proceso de transferencia. Se examinará, pues, no solamente cómo el Texto 2 ha adaptado el Texto 1 sino también en qué medida la política de selección de los elementos primeros y el proceso de transferencia se han producido en función del papel del Texto 2 en el nuevo polisistema.

El estudio del funcionamiento de la adaptación en el polisistema de llegada implica dos tipos de cuestiones: la primera afecta a la identificación de la adaptación fílmica como tal adaptación. No se trata de aproximarse a ella en función de relaciones predefinidas de fidelidad o adecuación al texto de partida sino de interrogarse sobre la medida en que es percibida y evaluada por el público y la crítica como adaptación. Habrá que considerar los datos textuales (referencias al texto o al autor primero en el interior de la historia) y peritextuales (los datos de los genéricos), examinar las numerosas actividades parafílmicas como campañas publicitarias, conferencias de prensa, documentales sobre el filme, los anuncios publicitarios en los diversos medios, la distribución de carteles, de folletos, etc. Se puede decir que un filme es anunciado como adaptación en la medida 
en que el texto y el autor primero son puestos en evidencia en las diferentes actividades fílmicas y parafílmicas.

La segunda cuestión afecta al funcionamiento y a la posición del filme adaptado en su contexto de llegada. Hay que interrogarse, entonces, sobre el carácter primario o secundario de esa función y sobre la posición central o periférica que dicha adaptación fílmica ocupará en el polistema 2 (Cattrysse, 1992: 34-36).

La recepción del filme como adaptación lleva a plantear la cuestión de los criterios seguidos para la selección del texto de partida y preguntarse por los mecanismos sistémicos que han operado en esa política de selección. Los elementos que determinan esa política constituyen, según Cattrysse, un conjunto complejo y evolutivo de factores que resaltan en el contexto (histórico, político, cultural, etc.) global en el que esa política se ha efectuado. El conjunto de normas preliminares se sitúa entonces, por una parte, en el contexto de partida y por otra en el contexto fílmico de llegada. No hay que excluir tampoco la interferencia de factores provenientes de los sistemas intermediarios, lo que nos conduce a otro concepto básico, el de la inmediatez de proceso de adaptación y a la pregunta de si los productores del filme se han basado en el texto original o han recurrido a textos intermedios.

Por lo que respecta a la consideración de la adaptación como proceso de transferencia, cabe estudiar dicho proceso haciendo abstracción de los elementos del texto de partida o como un proceso de transformación y transposición de dichos elementos; en un caso se atenderá a las normas de producción generales y en el otro a las normas transposicionales. Lógicamente, un estudio completo deberá integrar ambos tipos de normas.

El estudio de las normas transposicionales desplaza la perspectiva hacia la comparación de los contextos de llegada con los de origen. Tal comparación no es un fin en sí mismo sino que opera en función de la equivalencia realizada por la adaptación. La equivalencia, para Cattrysse, no es una categoría normativa pues no se define en función de relaciones preestablecidas de fidelidad o analogía respecto del texto original, sino que se trata más bien de una categoría descriptiva. La pregunta no será, pues, «¿hay equivalencia?» sino «¿cómo se ha realizado la equivalencia?» La respuesta conlleva diversas etapas: la primera, poner de relieve las semejanzas y las divergencias, los deslizamientos y los no-deslizamientos; la segunda, examinar si las semejanzas y las diferencias presentan cohe- 
rencias sistémicas. Cattrysse recuerda que es la recurrencia a opciones análogas en situaciones análogas lo que sugiere la presencia de normas determinadoras del proceso adaptador: Las semejanzas y los no deslizamientos sugieren que el texto 1 ha servido como modelo del proceso de adaptación; los deslizamientos, por el contrario, sugieren que los autores de la adaptación de han alejado del texto 1 para adoptar otro modelo que por una u otra razón convenía mejor a sus propósitos. En el primer caso se hablaría de normas de adecuación y en el segundo de normas de aceptabilidad.

Tras este largo resumen de las ideas de Cattrysse, exigido por la importancia de su aportación al fenómeno que nos ocupa, hay que referirse necesariamente al libro de Michael Serceau que, publicado después del anterior, constituye un intento de acercamiento global y omnicomprensivo a los problemas teóricos que plantea la adaptación cinematográfica. Mientras que el trabajo de Cattrysse es deudor de los presupuestos teóricos que aplicados al ámbito de la literatura desarrolla Even Zohar, Serceau lleva a cabo una revisión de todas las teorías precedentes en el intento de trazar un esquema explicativo total que permita abarcar el fenómeno desde todos los flancos.

Su punto de partida es la necesidad de superar los enfoques exclusivamente intratextuales, ya que, para él, la adaptación no es sólo una trasposición, una especie de calco audiovisual de la literatura, sino un modo de recepción y de interpretación de temas y de formas lingüísticas: en tanto que en ella se articulan el género, el relato, el personaje, la imagen, el mito, el tema o el mitema, la adaptación es, en sí misma, un modo de lectura. Quizá - afirma - a fin de cuentas, no se trata sino de un modo de cristalización o de una operación de recontextualización de la sustancia temática que circula entre la literatura y el cine, entre los diferentes estados históricos de la literatura y el cine, de la oralidad a la escritura, de una forma y de un modo de representación a otro.

Para Serceau no basta, pues, con decir que la adaptación se inscribe en las alternativas ilustración frente a recreación o fidelidad frente a originalidad. Es una intersección, y no solamente una confluencia, de literatura y cine (aunque también de literatura y teatro, de teatro y cine, de pintura y cine), de modos diferentes de semiotización, por lo que plantea el problema de la articulación, del retorno, de la obsolescencia o de la permanencia de diversas formas de la representación (Serceau, 1999: 9-10). 
Después de exponer en la introducción sus tesis de partida, desarrolla en la primera parte, y a lo largo de los cuatro apartados del capítulo primero, un extenso recorrido por las posturas teóricas en torno a la cuestión de la adaptación a partir de los años veinte, revisando y discutiendo los principales puntos abordados por los diversos teóricos del ámbito francés como Delluc, Artaud, Epstein, Metz, Bazin, Ropars, Zaraffa, etc. Esa primera parte se completa con otros dos capítulos dedicados respectivamente a la consideración de la adaptación como intersección y como lectura e interpretación.

En la segunda parte del libro, titulada «L'adaptation dans tous ses états», lleva a cabo una revisión pormenorizada de todos los elementos implicados en la práctica adaptativa, dedicando sendos capítulos a las cuestiones del tema, el relato, el personaje y la imagen que son abordados en profundidad desde un sólido conocimiento de las teorías literarias y cinematográficas, conocimiento que se completa con una amplia experiencia de espectador, de la que son buena muestra las más de 200 películas manejadas para ejemplificar las tesis que se defienden a lo largo del libro.

Después de ese exhaustivo recorrido, Serceau concluye que, en cuanto transferencia histórico-cultural, la adaptación está sometida a imposiciones y normas, a partir de las cuales se efectúa una apropiación cuyo sentido es preciso medir. Al ser el producto de una dialéctica entre la obra literaria, el contexto socio-histórico y los códigos de una cultura, es la permanencia o el desfase de los códigos culturales lo que está en juego. Toda adaptación testimonia de hecho, aunque no posea originalidad estética, una recepción de la obra literaria. No es posible, pues, desde esta perspectiva, atenerse exclusivamente a las relaciones inmediatas y explícitas que la adaptación mantiene con la obra original, pues ella es inseparable de la red de obras literarias y cinematográficas que la preceden y a la vez de aquellas que son producidas en el mismo campo histórico y cultural.

La adaptación puede ser, así, un simple producto de la ideología, de la estética, de la temática o de la mitología de una época. Puede también efectuar un desplazamiento, ser una condensación, una cristalización. Puede incluso ser más «fundadora» que la obra original: forma siempre abierta -asegura-, la adaptación es más que un lugar de encuentro, es un estado del texto al que pertenece la obra de referencia. Analizarla es apre- 
hender las lógicas temáticas y genéricas que existen en aquélla. Lejos de ser una forma bastarda o híbrida, la adaptación no tiene menos significación que las originales obras literarias o cinematográficas (Serceau, 1999: 174-175).

Dejando a un lado la obra de Serceau, imprescindible por tratarse hasta el momento del único intento de explicación global y exhaustiva del fenómeno de la adaptación cinematográfica, resultan de interés, por abordarlo desde perspectivas novedosas y esclarecedoras, otras aproximaciones teóricas contemporáneas.

Pueden citarse trabajos como los de Millicent Marcus, quien aunque no pretende la formulación de un modelo teórico de la adaptación pues se aplica al estudio de casos concretos, parte del presupuesto de diferenciar los dos estratos, historia y discurso, y por tanto del rechazo de los métodos comparatísticos tradicionales que juzgaban el filme adaptado con la mirada puesta en el texto- fuente (Marcus, 1993: 15). En la misma línea se mueve McFarlane, quien distingue entre elementos transferibles de un medio a otro, que serían los pertenecientes al plano de la historia, y elementos intransferibles por su dependencia de sistemas de significación diferentes, como son los correspondientes al plano del discurso; utilizará, así, el término transferencia para referirse al proceso mediante el cual ciertos elementos narrativos de la novela se revelan susceptibles de ser mostrados en el filme y adaptación para designar aquel proceso en el cual otros elementos novelísticos pueden encontrar equivalencias muy diferentes en el medio fílmico (McFarlane, 1996: 30).

Cabe mencionar también aquellas investigaciones que abordan la adaptación a partir de la noción de escritura, tomada de Roland Barthes, quien se refería mediante ese término al proceso de negociación expresiva entre la generalidad social del lenguaje y el estilo como un repertorio personal de mecanismos; distinguía, así, entre escritores (écrivants), aquellos que el escribir es transitivo, un mero medio hacia un fin, y autores (écrivains) o quienes conciben el escribir como una actividasd llena de sentido en sí misma; aplicada al caso concreto de la adaptación cinematográfica, se habla de escritura para distinguir aquellos trabajos en los que el adaptador lleva a cabo una auténtica creción de los meramente ilustrativos. MarieClaire Ropars, por ejemplo, aunque no trata concretamente el tema que nos ocupa, se referirá a toda adaptación como un proceso de reescritura (Ropars, 1970). 
Por su parte, André Gaudreault utiliza la noción de escritura para trazar unas fronteras bien diferenciadas entre lo cinematográfico frente a la narración escrita por una parte y frente a la «narración» escénica, por otra. Comienza asimilando el montaje a la narración escrita, aunque ello - precisa - no implique la total asimilación de lo fílmico a lo novelesco; para Gaudreault el montaje se articula sobre una mostración (término que implica representación, aunque no se confunda con él), que no existe en la novela y que sería el equivalente moderno de la diégesis mimética mientras que la narración lo sería de la diégesis no mimética. Señala que la mostración está ligada a elecciones que se efectúan en el momento del montaje. En consecuencia, el relato fílmico sería a la vez algo diferente del relato escénico y del relato escrito: se trataría de una escritura en tres tiempos en la medida que en él se articulan las tres operaciones de mise en scéne, mise en cadre y mise en chaîne (Gaudreault, 1988).

\section{LA ESPECIFICIDAD DE LA ADAPTACIÓN DE TEXTOS TEATRALES}

Existen, por otra parte, algunos estudios recientes que se centran en el caso concreto de la adaptación de textos teatrales; la especificidad de éstos frente a los textos narrativos determina una problemática particular de la adaptación que ha sido analizada con rigor y desde enfoques sugerentes por algunos estudiosos.

El trabajo más significativo en este sentido es, quizá, el de André Helbo (1997), quien sostiene que el acercamiento correcto al fenómeno de la adaptación ha de ser abordada en el seno de un trabajo sobre los procesos enunciativos: el camino será la combinación de procedimientos intrasemióticos e intersemióticos que permitirá la puesta en relación de los conjuntos textuales y contextuales. Por ello, su análisis se centra simultáneamente en la intencionalidad del autor y la atención espectatorial, afirmando que para que un filme sea una obra no basta con que el autor haya organizado diferentes estratos enunciativos alrededor de una intención estética, sino que es necesario que el espectador, abandonando la sola necesidad narrativa que le permite comprender el relato, busque otra lógica. 
Para él, el punto común entre teatro y cine radica en el acto de ostensión. Las imágenes fílmica y escénica comparten la categoría visual, pero la analogía no puede ir mucho más allá. El carácter efímero, aleatorio de la representación, la dependencia de la imagen teatral con relación al acto receptivo (tributario de la interacción del público, del tipo de sala, de la cultura del espectador) contrastan con la imagen fílmica, que una vez fijada, deja de depender del instante de la representación; se inscribe en operaciones narrativas (montaje, por ejemplo) que la ligan a la escritura literaria concluida antes del acto de la recepción. La elaboración del filme pasa por la elaboración de un guión distinto del texto teatral y por una operación de montaje, lo que plantea la cuestión de la narratividad fílmica, distinta de la diégesis mimética. Según esto, no se trata de considerar la escena y el filme como procedimientos más o menos equivalentes de inmersión perceptiva, sino de pensar la adaptación del teatro al cine como la sustitución de «visiones directas» por «visiones inducidas».

Para Helbo, la doble enunciación no es una característica del discurso fílmico, pues, salvo excepciones, se tiende a borrar al enunciador y a privilegiar el relato. El resultado es un efecto de modalidad asertiva, incluso de naturalización, propia del cine: si el teatro puede sacar partido del cartón piedra y erigirlo en símbolo, el cine tiende a privilegiar el efecto verdad y enmascara el cartón piedra para insertarlo en la verosimilitud; al contrario del teatro, la imitación debe ser siempre perfecta, inscribirse en una relación de conformidad con lo real. Por ello, la utilización de convenciones realistas o de símbolos (pone como ejemplo la figuración del agua en E la nave va, de Fellini) confieren al filme una dimensión teatral.

Sostiene, por otra parte, que toda creación es un proceso abierto, alimentado de herencias anteriores, hecho de acumulaciones, repeticiones, transformaciones y variaciones. Por ello, tanto las reescrituras de textos teatrales como sus adaptaciones cinematográficas se refieren explícita o implícitamente unas a otras, planteando el problema del conocimiento del contexto (la situación, las claves históricas) y del cotexto de la tradición (referencias implícitas, postulados en el espectador, conocimiento de versiones anteriores). A este respecto, concede una especial importancia a los paratextos en virtud de la función determinante que éstos pueden ejercer en la recepción de la obra teatral y cinematográfica: los programas, la actividad de marketing, las entrevistas y declaraciones de los responsables de 
la puesta en escena o del filme, etc., funcionan como señales institucionales que permiten circunscribir la intención del producto ${ }^{4}$. A ello hay que añadir la atención a las modalizaciones de dependencia cultural: las señales architextuales de pertenencia a un género, a una cultura, al tipo de repertorio, etc. pueden determinar el modo de recepción o rupturas significativas. La dinámica de una cultura determinada (normas, modelos, sistemas) contribuye a definir qué prácticas son las dominantes (frecuentes) o canónicas (prestigiosas). El análisis polisistémico subrayará en qué medida el contexto de la transposición, las normas y sistemas de la misma en la situación socio-cultural de partida y de llegada juegan un papel crucial.

Un apartado interesante del trabajo de Helbo lo constituye su intento de tipificar las posibilidades de adaptación del texto teatral a la pantalla; su clasificación comienza distinguiendo entre la captación directa de un espectáculo y la intervención que adapta la representación al medio fílmico. La primera sería el grado cero de la práctica adaptativa y se limitaría al archivamiento filmado de representaciones teatrales memorables, lo que es el caso también de las retransmisiones televisivas (en directo o en diferido) de un espectáculo teatral. Pero si la cámara puede proporcionar un testimonio fiel de un decorado o de una puesta en escena, no es seguro, en cambio, que pueda captar el movimiento de la significación, restituir una dramaturgia.

Dentro de la segunda vía distingue Helbo diversas posibilidades: la reconstrucción o grabación de diversas representaciones procediendo luego a seleccionar y montar los fragmentos; la reconstrucción creativa que consistiría en aprehender un material utilizado para el teatro y someterlo a un discurso cinematográfico alejado de la representación (pone como ejemplo el Marat-Sade, de Peter Brook) y la creación, en la que el acontecimiento teatral llevado a la pantalla no es tributario de la representación «preestilizada» sobre la escena, sino que está construido en función de la sola «ideología» de la cámara (dos ejemplos serían El baile, de

\footnotetext{
4 Para Helbo, el discurso cinematográfico, atento a legitimar la verosimilitud, debilita considerablemente la función distintiva del paratexto. A lo más subsisten ciertas señales peritextuales (precio de entrada, color sociológico de la sala de arte y ensayo, relación con realizaciones anteriores en el caso del remake) y epitextuales (carteles, campañas de entrevistas); tales signos intervienen una vez que el espectáculo está elaborado y sólo pueden influir en la recepción por parte del público.
} 
Ettore Scola y Macbeth, de Polanski). Helbo alude tambén a la existencia de prácticas intermedias, como la de utilizar decorados visiblemente teatrales pero con un lenguaje específicamente cinematográfico: Falstaff, de Welles, o Carmen y El rey Lear, de Brook.

Se plantea, por otra parte, el problema de los límites de la captación, preguntándose si es posible afrontar una filmación «inocente» que pretenda conservar la «objetividad» de la representación La respuesta es que la filmación implica la puesta en juego de una serie de procedimientos que, de un modo u otro, destruyen por su esencia una parte de la teatralidad. Por ello, más que de captación, entendida como réplica icónica de un espectáculo cuyos códigos permanecen inalterados, es preferible hablar de notación: operación que consiste en imaginar significantes e integrarlos en un sistema semiótico (fílmico) para trasponer la significación global (la dramaturgia, la teatralidad) de un sistema original.

François Jost, es otro de los teóricos que ha profundizado en el problema de la adaptación de textos teatrales en varios de sus trabajos (1991a, 1991b). Voy a exponer algunas de sus principales aportaciones en torno a una cuestión capital para abordar el tema de la adaptación de textos teatrales a la pantalla, el de las diferencias discursivas entre ambos medios, basándome en la conferencia pronunciada en el encuentro sobre Cine y teatro clásico en el marco del Festival de Almagro, en julio de 2000, pues en ella trazó un excelente resumen de sus ideas sobre la cuestión.

Para Jost, la principal divergencia entre teatro y cine consiste en que el primero es un arte para el cual la presunción de intencionalidad es más grande que en el segundo. Todo lo que aparece sobre la escena es premeditado, pues no existe en ella nada que no haya sido pintado o construido, mientras que en el cine es posible discutir sobre el grado de intencionalidad ex profeso de muchos detalles sonoros o visuales que nos llegan desde la pantalla. A partir de ello, establece que redundancia y ruptura son los dos rasgos formales que permiten caracterizar una información sonora o visual como ostensiva, es decir, que hacen que un detalle mostrado se convierta en un detalle ostensible. La redundancia es lo que permite comprender al espectador que la información transmitida es intencional, por lo que se trata de una intención narrativa, caracterizada por el hecho de que su pertinencia no existe más que en y por el relato y la comprensión de aquél por el espectador. 
La ruptura, por el contrario, aunque sea fácilmente detectable puede plantear problemas al espectador. Ante un ruido que no encaje con el decorado o una elipsis espacial demasiado brusca no está siempre claro si deben ser considerados como arbitrarios o responden a una intención discursiva. Para dotar de coherencia a una ruptura el espectador debe a veces buscar más allá de la función narrativa porque la ruptura no aumenta necesariamente su conocimiento del mundo diegético. Solamente manifiesta el deseo del realizador de comunicar algo. Es la propensión de lo visible a justificarse desde el punto de vista de la coherencia formal, plástica, etc., subordinada a una visión de conjunto lo que le dará pertinencia artística.

Preguntarse si el cine tiene más facilidad para mostrar las intencionalidades narrativas o discursivas supone reabrir el controvertido debate sobre la narración en teatro y en cine. Jost cita a este respecto a Schaeffer ${ }^{5}$, quien, apoyándose en que el teatro muestra que el hecho de contar una historia no tiene necesidad de ser asumido por un narrador, sostiene que «el espectador no ve el filme como algo que alguien le contase sino como un flujo perceptivo que es el suyo propio». Jost comenta que el razonamiento de Scheaffer parte del postulado de que pensar narratológicamente no implica tener en cuenta una instancia narradora, como nos demuestra el teatro, por lo que la asimilación de la ficción cinematográfica a la ficción teatral sólo es posible a partir del postulado de la reducción del filme a su dimensión escénica: «la representación quasi perceptiva de una secuencia de acontecimientos no es un acto narrativo sino que consiste en el hecho de poner ante los ojos (y los oídos) del espectador una secuencia de acontecimientos». En otras palabras, desde el momento en que la percepción audiovisual está implicada, no es posible hablar de relato: «desde el momento en que una secuencia es filmada, se deja ver y oír como una representación perceptivamente accesible de una secuencia de acciones; desde el momento en que es contada (en el sentido técnico del término), se da a leer como enunciada por un narrador.»

Para Jost, esta distinción entre representación y relato es una herencia de la antigua distinción entre mímesis y diégesis, entre los géneros en que el poeta desaparece tras los personajes y aquellos otros en los que habla en su nombre. Pero opina que esta anulación de la instancia mediadora,

5 El trabajo citado de Jean-Marie Schaeffer es Porquoi la fiction? Paris: Seuil, 1999. 
aunque puede servir para definir el teatro clásico tal como se representaba en su época (cuando no existía el director de escena), resulta difícil de mantener hoy en día porque significa rechazar la actividad mediadora de un eventual mostrador, despreciar la del espectador y negarse a comprender las diferencias entre cine y teatro. Sostiene, entonces que también en el teatro, «poner ante los ojos» implica que la materia dramática ha debido sufrir un proceso de selección (tanto en la composición del texto como en la elaboración de la puesta en escena) y que, por otra parte, el espectador de teatro no ve nunca exactamente lo que el director de escena pone delante de sus ojos ya que (cita a Ubersfeld) «la fabricación de la mirada en el teatro no es fruto de una fabricación anterior, sino el producto de un trabajo perceptivo del espectador en todos los momentos de la representación». Por ello, concluye que el teatro se distingue ontológicamente de toda adaptación cinematográfica por su manera de dirigir la mirada del espectador $\mathrm{o}$, mejor dicho, de indicarle qué es necesario mirar.

Partiendo de esta verdad incontestable de que el espectador está fijo en su asiento - continúa Jost-, el director de escena no puede actuar sobre la dirección de su mirada más que mediante la creación de rupturas: iluminación brutal, desplazamiento brusco del actor, apariciones, etc. Sin recurrir a procedimientos de ostensión, no puede impedir al espectador detenerse en tal o cual detalle, ampliar el rostro de un actor mediante los prismáticos, etc. En cambio el director de cine tiene la capacidad no sólo de atraer la atención del espectador hacia lo que él selecciona, sino incluso de liberarlo de su butaca. Por ello, afirma sosteniendo la idea que hemos visto defender a André Helbo, resulta menos fructífero considerar la escena y el filme como procedimientos más o menos equivalentes de inmersión perceptiva, que pensar en la adaptación del teatro al cine como la sustitución de «visiones directas por visiones inducidas».

En resumen, las diferencias de intencionalidad entre teatro y cine pesan sobre la recepción de lo visual y de lo auditivo por el espectador. En el cine son posibles, al menos, tres tipos de recepción correspondientes a los tres niveles de comprensión de la imagen que señala Schaeffer: la intransitiva (correspondiente a la visión ingenua, que no va más allá de lo que se muestra), la identificación referencial (el espectador duda entre una interpretación estética y la existencia de sentidos ocultos) y la construcción simbólica. 


\section{ALGUNAS APORTACIONES TEÓRICAS EN EL ÁMBITO ESPAÑOL}

Resultaría incompleta esta panorámica de no aludir a algunos de los trabajos sobre la adaptación cinematográfica que han visto la luz en España durante los últimos años y que constituyen en muchos casos importantes aportaciones a la cuestión.

Es preciso remontarse algunos años más allá del marco cronológico delimitado para aludir al temprano libro de Jorge Urrutia (1984), el primero en abrir la brecha desarrollando una serie reflexiones sobre la relación entre cine y literatura que abarcan varios frentes. Aunque el libro aborda con claridad y de modo sistemático varias cuestiones básicas de la teoría del cine, las reflexiones de mayor interés sobre nuestro tema son las desarrolladas en el capítulo «Notas metodológicas para el estudio de las relaciones del cine con la literatura» donde trata de definir el lugar que habría de ocupar la atención a las relaciones entre ambos medios en el marco de los estudios comparatísticos y se refiere a los diversos aspectos que abarcarían dichas relaciones. Respecto de la adaptación observa cómo el carácter de ésta ha ido evolucionando a lo largo de los años o se detiene a comentar la tipología establecida por Baldelli a la que añade una sexta posibilidad: la adaptación que usando la obra literaria como punto de partida llevase a cabo una reelaboración o crítica de la misma; se constituiría, así, en «asedio crítico» que propondría nuevas lecturas del texto en cuestión (Urrutia, 1984: 10-11). Por otra parte, en toda su argumentación está presente la necesidad de separar en el análisis de la adaptación el plano de la historia y el del discurso, por lo que, al preguntarse sobre la posibilidad de equivalencia entre el texto original y su adaptación, afirma que la estructura de una historia es independiente del lenguaje que la dé a conocer: «La correspondencia entre el plano de la expresión y el del contenido no se produce entre los elementos, sino entre las unidades. La narración gobierna profundamente la ficción. (...) La expresión actúa sobre la forma del contenido pero pudiera no ejercer influencia sobre la sustancia del contenido» (Urrutia, 1984: 78).

Tras él, especialmente en la última década, se ha producido en el ámbito español un incremente importante de la bibliografía sobre el tema de la adaptación, mucho más abundante en el campo de la aplicación práctica y de la explicación de casos concretos que el de los intentos teóricos; como sería imposible resumirla en estas páginas, me limitaré, al menos, a 
algunos trabajos del último tipo que sobresalen por su rigor al abordar el tema objeto de estas páginas; existen, obviamente, otros varios que han de ser citados, pero no me detendré en ellos ya que abordan el tema de la adaptación tangencialmente al no constituir su objetivo principal (Gimferrer, 1985 o Peña Ardid, 1992, dos de las aproximaciones más globalizadoras $\mathrm{y}$, a la par brillantes, que existen en nuestro ámbito sobre las relaciones entre la literatura y el cine) o no profundizan en la dimensión teórica (Quesada, 1986; Mínguez Arranz, 1998; Ríos Carratalá, 1999).

Uno de ellos es el libro de Virginia Guarinos sobre la adaptación teatral (Guarinos, 1996), en donde después de hacer un recorrido histórico por las relaciones entre cine y teatro y revisar la extensa bibliografía existente sobre el tema, presenta un riguroso planteamiento teórico sobre la adaptación de textos teatrales al cine.

Para Guarinos no puede hablarse de «teatro filmado», pues es una categoría inexistente. Siendo cierto que en el teatro lo más importante es construir situaciones y en el cine, en cambio, lo más importante es producir enunciados, el cine teatralizado siempre seguirá produciendo enunciados, aunque éstos conlleven en su interior más situaciones de enunciación que otros discursos fílmicos. Desde el momento en que hay una cinta que contiene el teatro, el discurso es la representación y no la representación es el discurso. Así, puede afirmarse que no sólo no existe un cine teatralizado desgajable del narrativo, sino que el teatro filmado no existe (Guarinos, 1996: 113-114).

En el teatro, al no ser narrativo, no pueden encontrarse similitudes de estructuras con la sintaxis de la narración fílmica, y además, puesto que es de naturaleza icónica y audiovisual, la puesta en escena se encuentra en la base de la cadena de producción fílmica, como material profílmico. No hay un texto escénico injertado en otro autónomo que lo engloba. Como afirma Pavis, «el teatro no existe como evento escénico filmado, sino como temática o como escenario para una historia recompuesta o reescrita para la pantalla (...) el que dice adaptación dice en efecto reescritura, replanteamiento de la intriga, del hecho dramático y escénico». No obstante, esa libertad existe con respecto a la obra en sí, en sus contenidos, pero no con respecto a la teatralidad como comunicación, como modo de emisión y recepción y que, por lo tanto, se refleja en el discurso. En la puesta en escena para cine teatralizado la transcodificación se hace pensando en el lugar que se le va a dar a la cámara. Se elimina lo teatral como 
teatro absorbido y para compensar, y que quede algo de lo teatral en la película, se vuelca la intención sobre un determinado tipo de sintaxis y de ver ese decorado que sí es profílmico. La puesta en escena profílmica no es teatral sino con vistas a la construcción de una narración. Lo teatral en teatro y en televisión viene por el contenido. Lo teatral en el cine teatralizado viene por la expresión intencionada, que, aun siendo teatral por el modo de ver del espectador, no sea puramente referencial (Guarinos, 1996: 65-67).

Un segundo título es la monografía de Sánchez Noriega (2000), que constituye un sólido intento sistematizador sobre el tema de la adaptación de textos literarios en donde se conjugan con habilidad las vertientes teórica y práctica. El libro, de gran claridad expositiva, aborda en primer lugar los aspectos teóricos, llevando a cabo una revisión de propuestas anteriores y ofreciendo posteriormente una completa y detallada tipología en la que resulta difícil encontrar alguna práctica adaptativa, que no sea considerada. La segunda parte es un intento sistematizador de las categorías de la teoría narratológica en su viabilidad para ser aplicadas al análisis del relato fílmico, mientras que la tercera se centra en el análisis de seis adaptaciones de diverso tipo, análisis que va precedido de un esquema teórico que el autor propone para tal operación.

El tercer libro que quiero mencionar es el de Luis Miguel Fernández sobre la presencia del mito de Don Juan en el cine español, en el que la revisión de las versiones cinematográficas va precedida de unas sólidas 47 páginas en las que esboza una teoría de la recreación fílmica (Fernández, 2002). Recreación y no adaptación, porque el autor intenta desbancar una noción que le parece inoperante pese a que siga empleándose por pura inercia; y es que — afirma— «en la transformación fílmica de un texto anterior no hay ninguna dependencia con respecto a éste sino una igualdad entre lenguajes diversos, por lo que difícilmente el filme podrá «adaptarlo» aunque sí lo recreará, lo volverá a producir partiendo de una situación diferente» (Fernández, 2002: 13). Tras pasar revista a las más importantes teorías que se han formulado sobre la mal llamada «adaptación», denunciando en la mayoría de ellas la tendencia a privilegiar el texto literario sobre el fílmico, se detiene especialmente en las propuestas de Cattrysse, cuyo intento de trasponer al estudio de la recreación cinematográfica la teoría de los polisistemas de Even Zohar (y el aprovechamiento de las mismas por Toury para explicar el fenómeno de la traducción) le parece la vía más rentable para abordar esa cuestión; 
por ello será la que empleará en el análisis de algunas de las recreaciones que el cine español ha hecho del mito de Don Juan, análisis que ocupa la segunda parte del libro. Las propuestas de Cattrysse suponen, como hemos visto, una ruptura definitiva con los teóricos, anteriores excesivamente anclados en la dependencia del filme con respecto al texto fuente, y la apertura de un amplio horizonte a las investigaciones sobre esta materia; en ello insiste Luis Miguel Fernández especialmente a la hora de valorar el nuevo filme en función de las relaciones de dependencia que se establecen en el polisistema de llegada, y de considerarlo, a la vez que como proceso de transferencia de un sistema a otro, como producto acabado, lo que llevará consigo la necesidad de tener presente todo lo relacionado con la actividad comercial y social del filme y su recepción y función en el polisistema receptor.

Detenerme en los numerosos artículos que se han ido incrementando durante los últimos años la bibliografía sobre el tema excedería el espacio de estas páginas. Me limito por ello a citar algunos que sobresalen por la atención dedicada a la vertiente teórica como Company, 1987; Villanueva, 1996 y 1999; García Templado, 1997 o Couto Cantero, 1999. No pueden dejar de mencionarse tampoco los numerosos volúmenes colectivos centrados en el análisis de las relaciones entre cine y literatura (algunos de ellos concretamente en las relaciones entre cine y teatro), fruto de encuentros o cursos diversos, en los que, pese a su desigual y heterogéneo contenido, pueden encontrarse algunas interesantes aportaciones centradas más en la consideración de los problemas teóricos que derivados de las prácticas adaptativas que en el análisis de casos concretos; entre ellos: Eguiluz et al., 1994; Ríos Carratalá y Sanderson, 1996 y 1999; Cantos, 1997; Castro de Paz et al., 1999; Peña Ardid, 1999; Vilches, 2001 o Romera Castillo, 2002. 


\section{REFERENCIAS BIBLIOGRÁFICAS}

Albéra, F. (1998). Los formalistas rusos y el cine. Poética del filme. Barcelona: Paidós.

ANDREw, D. (1984). Concepts in Film Theory. New York: Oxford University Press.

BALDELli, P. (1966). El cine y la obra literaria. La Habana: ICAIC.

BAZIN, A. (1990). ¿Qué es el cine? Madrid: Rialp.

Bettetini, G. (1986). La conversación audiovisual, Madrid: Cátedra.

Bluestone, G. (1971). Novels into Film. Berkeley: California University Press.

Bordwell, D. (1996). La narración en el cine de ficción. Barcelona: Paidós.

- y Thompsn, K. (1995). El arte cineamatográfico. Barcelona: Paidós.

CANTOS, A. (comp.) (1997). Arte, literatura y discurso cinematográfico. Málaga: Universidad (anejo XIII de Analecta Malacitana).

Casetti, F. y Di Chio, F. (1994). Cómo analizar un film. Barcelona: Paidós.

Castro de Paz, J. L., et al. (eds.) (1999). Cien años de cine. Historia, Teoría y Análisis del texto fílmico. Madrid: Visor Libros.

Cattrysse, P. (1992). Pour une théorie de l'adaptation filmique. Le film noir américain, Berna: Peter Lang.

Company, J. M. (1987). El trazo de la letra en la imagen. Madrid: Cátedra.

Corrigan, T. (1998). Film and Literature. Introduction and Reader. New Jersey: Prentice Hall.

Couto CAntero, P. (1999). «Teoría de la transposición cinematográfica. En defensa de los nuevos soportes. Discurso literario $v s$. discurso fílmico». En J.L. Castro de Paz et al., 213-235.

EguiLuZ, F. (comp.) (1994). Trasvases culturales: literatura, cine, traducción. Vitoria: Universidad del País Vasco. 
EikHENBAuM, B. (1998). «Literatura y cine». En Albèra, 197-202.

Fernández, L. M. (2000). Don Juan en el cine español. Hacia una teoría de la recreación fílmica. Santiago de Compostela: Universidad.

García, A. (1990). L'adaptation du roman au film. París: DiffusionDujaric.

García Templado, J. (1997). «La homología estructural en las adaptaciones cinematográficas». Signa 6, 259-271.

Gaudreault, A. (1988). Du littéraire au filmique. París: MéridiensKlincksieck.

— y Jost, F. (1995). El relato cinematográfico. Barcelona: Paidós,

GiMfERRER, P. (1999). Cine y literatura. Barcelona: Planeta.

GuARINOS, Virginia (1996). Teatro y cine. Sevilla: Padilla Libros.

GutiérRez Carbajo, F. (1993). Literatura y cine. Madrid: UNED.

Helbo, A. (1997). L'adaptation. Du théâtre au cinéma. París: Armand Collin.

Jost, F. (1991a). «Le film comme oeuvre». Protée 19, Chicoutimi.

— (1991b). «Le lu et le dit». Cinema et littérature. Bruxelles: VUB Press.

- (2000). «Théâtre et cinéma classique français. Du théâtre a l'image», conferencia en el encuentro sobre Cine y teatro clásico en Festival de Almagro (copia cedida por el autor).

McDugal, S. Y. (1985). Made into Movies: From Literature to Film. Orlando: Harcourt Brace Jovanovich, Publishers.

MARCus, M. (1993). Filmmaking by the Book. Italian Cinema and Literary Adaptation. Baltimore and London: John Hopkins University Press.

McFarlane, B. (1996). Novel to Film. An Introduction to the Theory of Adaptation. Oxford: Clarendon Press.

Mínguez ARRAnZ, N. (1998). La novela en el cine. Análisis comparativo de dos discursos narrativos. Valencia: Ediciones La Mirada.

PeÑa ARDID, C. (1992). Literatura y cine. Una aproximación comparativa. Madrid: Cátedra. 
- (ed., 1999): Encuentros sobre literatura y cine. Teruel y Zaragoza: Instituto de Estudios Turolenses y Caja de Ahorros de la Inmaculada.

QUeSADA, L. (1986). La novela española y el cine, Madrid: Ediciones JC.

Ríos Carratalá, J.A. (1999). El teatro en el cine español. Alicante: Generalitat Valenciana /Instituto Juan Gil-Albert.

- y SANDERSON J. (comps.) (1996). Relaciones entre el cine y la literatura: un lenguaje común. Alicante: Universidad.

- (comps) (1999). Relaciones entre el cine y la literatura: el teatro en el cine. Alicante: Universidad.

Romera Castillo, J. (ed. 2002). Del teatro al cine y la televisión en la segunda mitad del siglo XX. Madrid: Visor Libros.

Ropars-Wuilleumier, M.C. (1970). De la littérature au cinéma: genèse d'une écriture. París: Armand Colin.

SÁnchez Noriega, J. L. (2000). De la literatura al cine. Teoría y análisis de la adaptación. Barcelona: Paidós.

SEgER, L. (1993). El arte de la adaptación. Madrid: Rialp.

SERCEAU, M. (1999). L'adaptation cinématographique des textes littéraires. Théories et lectures. Liège: Éditions du Céfal.

Toury, G. (1980). In Serch of a Theory of Translation. Tel Aviv: The Porter Institut for Poetics and Semiotics.

UrRUtia, J. (1983). Imago litterae. Sevilla: Alfar.

VAnoye, F. (1995). Récit écrit-Récit filmique. París: Nathan.

VILCHES, Ma F. (ed.) (2001 y 2002). Teatro y cine: la búsqueda de nuevos lenguajes expresivos. Monográfico de ALEC, vol. 26, issue 1 y vol. 27, issue 1.

Villanueva, D. (1999a). «Novela y cine, signos de narración». En C. Peña Ardid (ed.), 185-209.

- (1999b). «Los inicios del relato en la literatura y en el cine». En J.L. Castro de Paz et al. (eds.), 213-235.

Wagner, G. (1975). The Novel and the Cinema. London: Tantivy Press. 